Rev. Elev. Méd. vét. Pays trop., 1975, 28 (1) : 9-11

\title{
Premiers cas au Tchad de botulisme animal (type C) : Intoxination de dromadaires par l'eau d'un puits
}

\author{
par A. PROVOST (*), P. HAAS (*) et M. DEMBELLE (**)
}

RESUME

Les auteurs relatent les circonstances d'apparition d'un foyer de botulisme à $C$. botulinum $C$ apparu chez des dromadaires ayant bu l'eau d'un puits contaminé par le cadavre d'un animal d'espèce inconnue.

Commentant l'enzootie botulique bien connue du sahel sénégalais, DOUTRE (2) concluait : "Il se peut que l'affection existe et soit ignorée dans d'autres zones sahéliennes situées sur le même parallèle, où l'élevage extensif trouve également des conditions difficiles en fin de saison sèche. "Cette réflexion judicieuse vaut pour le Tchad où, autour de certains forages profonds, sont apparues des zones de désertification par surpâturage, recréant les conditions écologiques du Ferlo sénégalais où s'est développé le botulisme. Aussi est-ce avec une légitime appréhension que depuis plusieurs années le service des diagnostics du Laboratoire de Farcha s'était préparé à effectuer le diagnostic rapide de botulisme dans d'éventuelles mortalités d'origine indéterminée qui se seraient manifestées autour de forages profonds. Les premiers cas tchadiens de botulisme animal devaient pourtant se manifester en d'autres circonstances.

\section{Relation du cas}

Le 28 juin 1974, l'un de nous (M. D.) faisait une toumée dans le nord du département du Kanem, entre Mao et Zigueye. A environ $150 \mathrm{~km}$ de Mao, autour des puits de Bagaye et de Chaallah, il notait la présence de nombreux

(*) Laboratoire de Recherches Vétérinaires de Farcha, B.P. 433, N'Djamena, Tchad.

(**) Service de l'Elevage, Mao, Kanem, Tchad. cadavres de chameaux. D'autres animaux présentaient une difficulté de la station debout, avec parésie des membres postérieurs. Couchés, ils allongeaient le cou et la tête sur le sable ou se mettaient en position d'auto-auscultation. La mort devait intervenir quelques heures plus tard dans la même position. Dans une population de 150 chameaux, il put ainsi voir 40 malades et dénombrer 45 cadavres.

Les éleveurs ignoraient tout de la nature de la maladie de leurs animaux mais la brusquerie de son apparition et la rapidité de son évolution leur ont fait suspecter une intoxication. Ils l'ont rapportée à l'abreuvement des chameaux, la veille, au puits de Chaallah d'où l'un d'eux avait remonté dans le "chalouf" (peau de chèvre servant à puiser l'eau) des touffes de poils adhérentes à des fragments de peau macérée. Les premiers signes de l'intoxication devaient se produire le soir même de l'abreuvement; 20 chamelles mouraient en quelques heures.

On préleva un métacarpe d'un cadavre frais et l'eau du puits.

\section{Examens de laboratoire}

Les cultures aérobies et anaérobies de la moelle métacarpienne en milieux bactériologiques usuels sont restées stériles. 
L'eau prélevée, filtrée sur disque Millipore HA et inoculée en quantité de $1 \mathrm{ml}$ par voie intrapéritonéale à des souris de $16-20 \mathrm{~g}$ provoque des paralysies flasques typiques, puissamment évocatrices, du botulisme.

L'échantillon d'eau est repris, chauffé $5 \mathrm{mn}$ à $100^{\circ} \mathrm{C}$ puis centrifugé. Le culot de centrifugation est ensemencé en bouillon VF glucosé anaérobie. Après 5 jours de culture, le surnageant de centrifugation du milieu de culture provoque la mort des souris à la dose de $0,001 \mathrm{ml}$. La toxinotypie botulique permet d'identifier la toxine $C$.

En gélose profonde ont été isolées des colonies lenticulaires. L'absence ou la pauvreté du métabolisme protidique et glucidique font pencher pour le type $\beta$ de Clostridium botulinum $\mathrm{C}$.

Au total, on est en présence d'une intoxination aiguë des chameaux par l'eau d'un puits renfermant la toxine botulique $\mathrm{C}$.

\section{DISCUSSION}

Alors que l'on s'attendait à devoir trouver un jour ou l'autre au Tchad, tout spécialement en ces années de sécheresse, des cas de "maladie des forages " analogues dans leur apparition à ceux du Sénégal, c'est un foyer d'intoxination plus classique qui a été découvert.

Il possède une forte ressemblance avec le botulisme d'origine hydrique qu'a décrit DOUTRE (3) au Sénégal; seule l'espèce de l'animal contaminateur n'a pu être précisée. On reste frappé du fait que, ni dans la relation de cet auteur, ni dans le foyer que nous avons observé, on ne signalait de maladie humaine; or, à Chaallah, les éleveurs ont bu l'eau du puits. On sait pourtant, depuis que PREVOT (5) l'a montré, que les toxines $\mathrm{C}_{\alpha}$ et $\mathrm{C}_{\beta}$ sont actives chez l'homme. En dehors d'une hyposensibilité éventuelle d'espèce, peut-être est-ce une question de quantité de liquide ingéré qui joue, la prise d'eau d'un chameau étant, toutes proportions gardées, bien supérieure à celle d'un homme.

Au demeurant, le problème posé par la contamination du puits de Chaallah reste grave. Malgré nos appels, il ne paraît pas que l'autorité administrative ait réagi pour décontaminer le puits ni faire disparaître les ossements des chameaux. Il est donc possible que l'on assiste, dans les mois et années à venir, à l'éclosion de foyers plus graves et plus disséminés de botulisme, selon l'étiopathogénie qu'ont invoquée DOUTRE et CHAMBRON (4).

Le cas rapporté de botulisme animal est le premier au Tchad et en Afrique centrale. Il vient derrière un petit foyer de botulisme humain de type $D(1)$ apparu après consommation d'un jambon cru de porc domestique, qui a donc une toute autre génèse. Premier à être observé et identifié, il est pourtant fort probable que de tels cas d'intoxination existent depuis longtemps car la tradition orale des éleveurs leur enseigne que l'eau des puits où sont tombés des chiens ou des singes devient toxique pour leurs animaux.

\section{SUMMARY}

First cases of animal botulism (type $C$ ) in Chad : intoxination of dromedaries by the water from a well

The circumstances of an outbreak of botulism due to $\mathrm{Cl}$. botulinum $\mathrm{C}$ are related; dromedaries were intoxinated by drinking the water from a well contaminated by the carcase of an animal of unknown species.

\section{RESUMEN}

Primeros casos en Chad de botulismo animal (tipo C) :
intoxinación de dromedarios por el agua de un pozo

Los autores indican las circunstancias de aparición del botulismo con Cl. botulinum $C$ encontrado en dromedarios que habian bedido el agua de un pozo contaminado por el cadaver de un animal de especie desconocida. 


\section{BIBLIOGRAPHIE}

1. DEMARCHI (J.), MOURGUES (C.), ORIO (J.) et PREVOT (A. R.). Existence du botulisme humain de type D. Bull. Acad. nat. Méd., 1958, 142 : 580582.

2. DOUTRE (P.). Le botulisme animal au Sénégal. Bull. Off. int. Epiz., 1967, $67 ; 1497-1515$.

3. DOUTRE (P.). Fréquence au Sénégal du botulisme animal d'origine hydrique. Rev. Elev. Méd. vét. Pays trop., 1969, 22 : 29-31.
4. DOUTRE (P.) et CHAMBRON (J.). Le botulisme des ruminants et des équidés au Sénégal et en Mauritanie, conséquence pathologique des troubles nutritionnels. Econ. Méd. anim., 1971, 12 : 116-129.

5. PREVOT (A. R.). Les bactéries anaérobies. Paris, Dunod, 1967 et Bull. Acad. nat. Méd., 1955, 139: 355. 